\title{
Intra-articular infiltration of adipose-derived stromal vascular fraction cells slows the clinical progression of moderate-severe knee osteoarthritis: hypothesis on the regulatory role of intra-articular adipose tissue
}

Juan Pedro Lapuente ${ }^{1}$, Severiano Dos-Anjos ${ }^{2}$ and Alejandro Blázquez-Martínez ${ }^{2^{*}}$

\begin{abstract}
Background: The infiltration of the stromal vascular fraction (SVF) of autologous adipose tissue to treat osteoarthritis has been used for several years demonstrating its safety and noticeable efficacy. This article presents clinical data from patients afftected by moderate and severe knee osteoarthritis demonstrating safety and clinical efficacy of the treatment when this autologous cell product is injected in the knee joint and patients evaluated post-operatively after 1 year. However, what do we know about the mechanism that underlies this clinical improvement? This article proposes, for the first time in our opinion, a hypothesis of the mode of action that involves structural and molecular interactions between SVF and infrapatellar fat pad (IFP). As consequence, there would be a re-education of intra-articular adipose tissue, which we consider a key player for the clinical effect observed in the mid and long term mainly due to immuno-regulatory mechanisms.
\end{abstract}

Methods: This is a retrospective and not controlled study that evaluated 50 patients (100 joints) ranging from 50 to 89 years old, separated by age cohorts. Clinical efficacy was assessed using the Lequesne, WOMAC, and VAS scales, by ultrasound control and quantification of the biochemical profiles of synovial fluid.

Results: There were no serious adverse effects. All the indexes studied showed a significant clinical improvement after 1-year follow-up for all ages and OA degree groups. This finding was correlated with the ultrasound observations and biochemical data, which show a marked decrease in catabolic and pro-inflammatory molecules (MMP-2, IL-1B, IL-6, and IL-8) and significant increase for anabolic and anti-inflammatory molecules (IGF-1 and IL-10).

Conclusions: We conclude that intra-articular SVF infiltration for knee OA treatment is safe and effective during 1 year. We propose that applied SVF cells cause a cascade of molecular and structural events that, through complex interactions between IFP and SVF, re-educating the intra-articular fatty tissue towards a homeostatic, protective, and anti-inflammatory function, which will ultimately promote the restructuring and regeneration of damaged tissues.

Keywords: Knee osteoarthritis, Gonarthrosis, Adipose tissue, Mesenchymal stem cells (MSCs), SVF, Infrapatellar fat pad, Hoffa's fat, Cartilage regeneration

\footnotetext{
* Correspondence: alejanb@gmail.com

${ }^{2}$ Lyposmol Biotech, Isabel Colbrand, 6, 28050 Madrid, Spain

Full list of author information is available at the end of the article
}

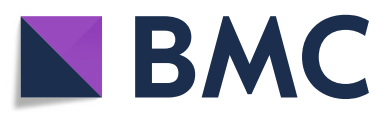

( The Author(s). 2020 Open Access This article is licensed under a Creative Commons Attribution 4.0 International License, which permits use, sharing, adaptation, distribution and reproduction in any medium or format, as long as you give appropriate credit to the original author(s) and the source, provide a link to the Creative Commons licence, and indicate if changes were made. The images or other third party material in this article are included in the article's Creative Commons licence, unless indicated otherwise in a credit line to the material. If material is not included in the article's Creative Commons licence and your intended use is not permitted by statutory regulation or exceeds the permitted use, you will need to obtain permission directly from the copyright holder. To view a copy of this licence, visit http://creativecommons.org/licenses/by/4.0/. The Creative Commons Public Domain Dedication waiver (http://creativecommons.org/publicdomain/zero/1.0/) applies to the data made available in this article, unless otherwise stated in a credit line to the data. 


\section{Background}

The EPISER study affirms that in 2020, knee osteoarthritis (OA) will be the fourth cause of disability in the world, and it is estimated that currently affects around 5 million people in Spain, being the chronic pathology that requires more health resources. It is estimated that the prevalence of gonarthrosis in Spain is $10.2 \%$ and that half of the population aged 50 years or older would have radiological signs of this pathology. For people aged between 60 and 69 years, the prevalence of symptomatic gonarthrosis is $28.6 \%$ and $33.7 \%$ in those over 70 years [1].

The different therapeutic options available to treat this pathology are complex, with more than 50 modalities of both pharmacological and non-pharmacological treatments [2], being the most common treatments the use of corticosteroid drugs, physiotherapy, injection of hyaluronic acid or platelet rich plasma. However, these traditional treatments, except the use of prostheses for very severe cases, have modest clinical efficacy and may have relevant adverse effects [3]. Moreover, these treatments fail to regenerate damaged articular cartilage but instead aim to reduce pain and/or maintain or improve joint function. Another option used with acceptable clinical results is autologous chondrocyte transplantation for chondral defects [4]. This option presents some disadvantages inherent to the chondrocyte's own nature as well as the need for cell culture expansion: these cells are differentiated and produce fibrocartilage instead of hyaline cartilage [5]. On the other hand, the infiltration of both culture-expanded mesenchymal stem cells (MSCs) [6] and the stromal vascular fraction (SVF) of adipose tissue $[7,8]$ in osteoarticular pathology with degenerated cartilage has promising results. This new therapeutic approach using adipose-derived cells slows the disease progression and also improves joint function and pain without serious adverse effects, promoting a significant reduction of cartilage defects by regeneration of hyaline cartilage [6].

The immunomodulatory properties of adipose tissue MSCs are well known [9], but requires a homogeneous population of MSCs that meets the standards for their identification [10] and allows to determine exactly the number of grafted cells. Ensuring the reproducibility of the clinical procedure needs an in vitro cell culture expansion phase, and this is considered substantial manipulation, and thus classified as an ATMP (Advanced Therapy Medicinal Product), which implies the need to satisfy a rigorous regulation for its clinical use in Europe (EMA/CAT/852602/2018). To solve this limitation, there are medical devices commercially available on the market that allow the direct adipose tissue processing in the operating room to obtain SVF cells with minimal manipulation, so they are not considered as advanced therapies. The situation could be noticeably different in other countries. The regulatory framework stablished by the FDA in the USA is based on the 21 CFR (Code of Federal Regulations) 1271, and specifically the HCT/P (Human Cells, Tissues and Cellular and Tissue Based Products) 351. This process, in principle, requires an IND (Investigational New Drug) application that ends eventually in a Biologics License Application. However, different approaches are being discussed to facilitate these cellular treatments in North America: 21st Century Cures Act, accreditation standards for facilities or developing National Registries for Cell Therapies. Some Asian nations, such as Japan and South Korea, are optimizing their regulatory paths in some instances, to consider different evaluations based on adaptive licensing or conditional marketing approvals. Anyway, in all cases the interpretation of minimal manipulation and homologous use are the key concepts involved.

However, the amount of MSCs present in these cell preparations is usually lower than in treatments with culture expanded cells, although this does not necessarily imply less clinical efficacy [11]. Moreover, the heterogeneous cell composition of the SVF, which includes progenitors and differentiated cells of diverse origin (hematopoietic, endothelial, and stromal), might improve the treatment effectiveness. This phenomenon could occur through the maintenance of the present MSCs and their functions, as well as molecular and structural synergistic mechanisms. In fact, in studies with freshly obtained SVF, Traktuev et al. demonstrated that certain factors produced by the MSCs present in SVF, such as VEGF, help the migration and better survival of endothelial precursors (EPCs), which in turn produce PDGF$\mathrm{BB}$ that allows MSCs to proliferate and migrate to the site of tissue damage $[12,13]$. They also describe, both in vitro and in vivo, physical interactions between MSCs and endothelial cells (ECs) in which ECs form stabilized vascular structures due to the support of MSCs. Moreover, in 2011, Koh et al. demonstrated that direct subcutaneous SVF grafting can create a deep vascular network through disassembly and reassembly of blood endothelial cells at the implantation site, connected with the host vessels forming a functional circuit [14]. The SVF obtained from adipose tissue also contains a significant proportion of cells involved in immunoregulatory functions and vascular remodeling of hematopoietic origin. According to Morris et al. [15], macrophages $(\mathrm{CD} 11 \mathrm{~b}+)$ resident in rodent adipose tissue constitute $20 \%$ of the cells obtained in SVF, and of these, $70 \%$ are positive for CD301, a marker of M2 macrophages (with anti-inflammatory and proangiogenic function) [16]. Koh et al. described the role of SVF macrophages in vascular assembly, noting that macrophages were necessary for proper vascular-structural organization. There are other pathological and therapeutic scenarios that 
emphasize the roles of SVF immune cells. For example, in the fat grafting procedures performed by Dong et al. [17], the inclusion of SVF in the fat grafts leads to increased expression of CD206 (another M2 macrophage phenotype marker) and a negative regulation of the proinflammatory agents IL-1 $\beta$ and IL-6.

There are several studies that seek to identify the mechanisms of action of MSCs in OA, and many of them demonstrate the importance of the paracrine activity of these cells in the inflammatory process and the extracellular matrix remodeling, even suggesting that there is an activation of the anti-inflammatory effect of MSCs caused by the pathological, pro-inflammatory microenvironment of the lesion [18-21]. But in our opinion, there is no detailed model that describes the mode of action involving immunomodulatory mechanisms combined with structural and molecular synergies between the SVF and infrapatellar fat pad (IFP), the latter taken as the authentic paracrine regulatory body that is the key player in the development of the disease. From this new point of view, the present study aims to assess the clinical efficacy of SVF intra-articular injection in osteoarticular knee pathology, in 50 patients with bilateral knee OA $(n=100)$ divided by age cohorts, as well as discussing the possible underlying mechanism of action.

\section{Methods}

\section{Study design and population distribution}

This retrospective and not controlled clinical study describes the treatment of 50 patients (selected randomly) who attended our clinic between 2014 and 2016, who were administered SVF intra-articularly on both knees and completed the 1-year period of treatment follow-up (without control group). The patients presented grade III or IV knee osteoarthritis (bilaterally) according to the Kellgren-Lawrence scale, confirmed by clinical evaluation, ultrasound, and magnetic resonance imaging and/ or radiography. All patients enrolled had failed with previous conventional treatments commonly used in the Spanish National Health System and had been recommended for joint replacement with a prosthesis. All the patients included in this study were informed in a personal interview by the medical staff with written information, after which they signed the consequent informed consents. All patients assumed the expenses related to the treatment, except those costs associated with the SVF processing device and the biochemical determinations in synovial fluid. Patients with severe local or systemic problems were excluded.

The group undergoing treatment was composed of patients aged between 50 and 89 years, affected by bilateral gonarthrosis grade III (50\%) and grade IV (50\%), of which 28 were men and 22 women, distributed by age cohorts (21 patients from 50 to 59 years, 17 from 60 to 69 years, 4 from 70 to 79 years, and 8 from 80 to 89 years) and physical assessment. The 50- to 59-year-old group contains 26 affected knees of grade III and 16 grade IV gonarthrosis, the 60- to 69-year-old group contains 18 affected knees of grade III and 16 grade IV gonarthrosis, the group of 70 at 79 years of age contains 4 knees affected by gonarthrosis grade III and 4 by grade IV, and the group from 80 to 89 years old contains 2 knees affected by gonarthrosis grade III and 14 by grade IV.

\section{Clinical outcomes}

The results were evaluated using patient-reported questionnaires using the Visual Analogue Scale (VAS) assessment scale for pain and the Western Ontario and McMaster Universities Osteoarthritis Index (WOMAC) and Lequesne Index [22] for OA disease evaluation before treatment and at 3 months, 6 months, and 1 year after SVF infiltration.

The molecular profile of the synovial fluid was also quantified before treatment and at the end of the followup period ( 1 year), and subjective assessments were performed by anamnesis and clinical examination with the main objective of identifying possible adverse effects. On the other hand, the Spanish version of the CRES-4 scale [23] was used to assess patient satisfaction after treatment. An initial and final (after 1 year) articular ultrasound control was also included using an ultrasound device E-CUBE 7 (Alpinion Medical Systems Co., Gyeonggi-do, Korea), following the protocol defined by Grassi et al. [24]. Briefly, joint effusion was defined as the presence of hypoechoic content in the suprapatellar recess greater than $4 \mathrm{~mm}$ of anteroposterior maximum diameter. The effusion was subjectively quantified in 4 stages ( 0 absence, 1 mild effusion, 2 moderate, 3 intense). Likewise, 3 ultrasound parameters of the femoral articular cartilage were evaluated: clarity, integrity of the cartilage-soft tissue interface, and thickness in millimeter in the following 5 locations: external condyle, internal condyle, and immediately suprapatellar intercondylar recess and $1.5 \mathrm{~cm}$ above. The clarity of articular cartilage was classified semiquantitatively in 4 degrees: $0=$ absence of internal echoes, $1=$ minimal presence, $2=$ moderate presence, and $3=$ intense presence. The integrity of the cartilage-soft tissue interface was scored subjectively in 4 stages: $0=$ normal, $1=$ slight changes, $2=$ moderate, and $3=$ intense. The final score of the clarity, integrity, and thickness parameters resulted from the average of the scores in the 6 anatomical locations mentioned.

\section{SVF isolation}

To obtain and process adipose tissue, the ADSC System commercial kit (Lyposmol Biotech, Madrid, Spain) was 
used in strict accordance with the manufacturer's instructions. Briefly, each patient included in the study was performed a lipoaspirate under local anesthesia (tumescent Klein's solution; all components from B. Braun, Melsungen, Germany) of the abdominal area in order to obtain $60 \mathrm{ml}$ of adipose tissue to be subjected to enzymatic digestion with collagenase I and II in order to isolate, by centrifugation, the SVF. The resulting SVF was resuspended in Ringer Lactato (B. Braun), and the presence of active collagenase before infiltration was ruled out using the screening test included in the same kit.

\section{SVF characterization}

As a quality control, SVF cells were counted using the trypan blue exclusion method and was used with the automatic counter TC20 (Bio-Rad, CA, USA) on a $10 \mu \mathrm{l}$ aliquot obtained directly from the SVF sample.

For phenotypic characterization by flow cytometry, $0.5 \mathrm{ml}$ aliquots were taken from three independent samples randomly selected to undergo erythrocyte lysis by hyposmotic shock (ZenBio, NC, USA) and then filtered through a 50- $\mu \mathrm{m}$ nylon mesh. The obtained cell solution was diluted in phosphate buffer without $\mathrm{Ca} 2+$ or $\mathrm{Mg} 2+$ (PBS, Merck KGaA, Darmstadt, Germany) 1:10 to obtain a diluted working cell solution, which was incubated for $15 \mathrm{~min}$ at room temperature and dark with the following fluorochrome conjugated antibodies: CD45-FITC, CD31-PE, CD34-PerCP, and CD146-PerCP (all from Sysmex, Kobe, Japan). For the exclusion of dead cells, DAPI was used, and for the exclusion of doublets the size and area parameters were faced. For the adjustments of the voltages and the compensations the appropriate controls were used (conjugated isotypes and markers one by one, respectively). For the acquisition of the samples, a BD FACSCelesta flow cytometer (Becton Dickinson, NJ, USA) equipped with the BD Diva software (Becton Dickinson) was used. Flowing software 2.5.1 (Perttu Terho, Turku, Finland) was used to analyze the results.

\section{Synovial fluid extraction and analysis of the molecular profile}

As a complement to the clinical data observed during the follow-up of patients treated by intra-articular SVF infiltration, we quantified the synovial fluid levels of proinflammatory cytokines (IL1 $\beta$, IL6, and IL8), antiinflammatory cytokines (IL10), catabolic (MMP2), and anabolic (IGF1) factors, before and 12 months after the treatment. Briefly, 1 to $2 \mathrm{ml}$ of synovial fluid was obtained using a $21 \mathrm{G}$ needle (Becton Dickinson). Immediately after extraction, it was frozen at $-80{ }^{\circ} \mathrm{C}$ in cryovials (Eppendorf, Hamburg, Germany) until quantification. ELISA tests were carried out following manufacturer's instructions (all obtained from Wuhan Fine
Biotech Co., Wuhan, Hubei, China) and quantified in a Microplate Absorbance Reader (iMark TM, BioRad, Hercules, CA, USA).

\section{SVF infiltration}

The volume of SVF cell suspension per knee joint was adjusted to $7 \mathrm{ml}$ using Lactated Ringer and then injected intra-articularly (and into the Hoffa's fat or IFP) using ultrasound guided injection with a 21 gauge needle (Becton Dickinson).

\section{Statistical analysis}

The significance $(p<0.05)$ of the data was analyzed with the Wilcoxon range non-parametric distribution test using Excel program (Microsoft, CA, USA). Each joint treated was taken into account independently for statistical analysis and clinical evolution.

\section{Results}

\section{Clinical outcomes}

In all scales used and age cohorts studied, we have found statistically significant differences between the baseline and the evaluation after 12 months $(p<0.05$, nonparametric Wilcoxon test). Furthermore, the age or sex of the patients does not influence the clinical outcome. Thus, we decided to evaluate the global trend of the study group as a whole, regardless of age group or sex. As expected, the differences continued to be statistically significant for all scales.

The initial mean values of the Lequesne index were 12.1 for OA grade III, and 13.77 for grade IV, registering final mean values of 1.76 at 12 months after implantation for grade III, and 5.05 for grade IV (Fig. 1a, b).

The total WOMAC score was 41.04 (mean values) for patients with grade III osteoarthritis and 52.8 for those with grade IV, obtaining a final average 12 months after SVF implantation of 6.18 for patients with OA grade III and 23.8 for grade IV (Fig. 1c, d).

The pain evaluation using the VAS index showed an important decrease in all age groups. The initial mean values were 7.08 for grade III osteoarthritis and 7.70 for grade IV, registering a final mean of said index of 2.12 at 12 months after implantation for grade III and 3.96 for grade IV (Fig. 1e, f).

If we analyze the evolution of pain by studying the average obtained in the scores of the three scales used in its assessment, we observe that in the group of gonarthrosis grade III there is a mean percentage decrease in pain of $74.44 \%$ at 12 months after performing the intraarticular SVF implantation. In the grade IV gonarthrosis group, an average percentage decrease of $54.11 \%$ of pain reduction was observed 12 months after the implant. The highest perception of improvement in the grade III OA group is maintained if we analyze the satisfaction 


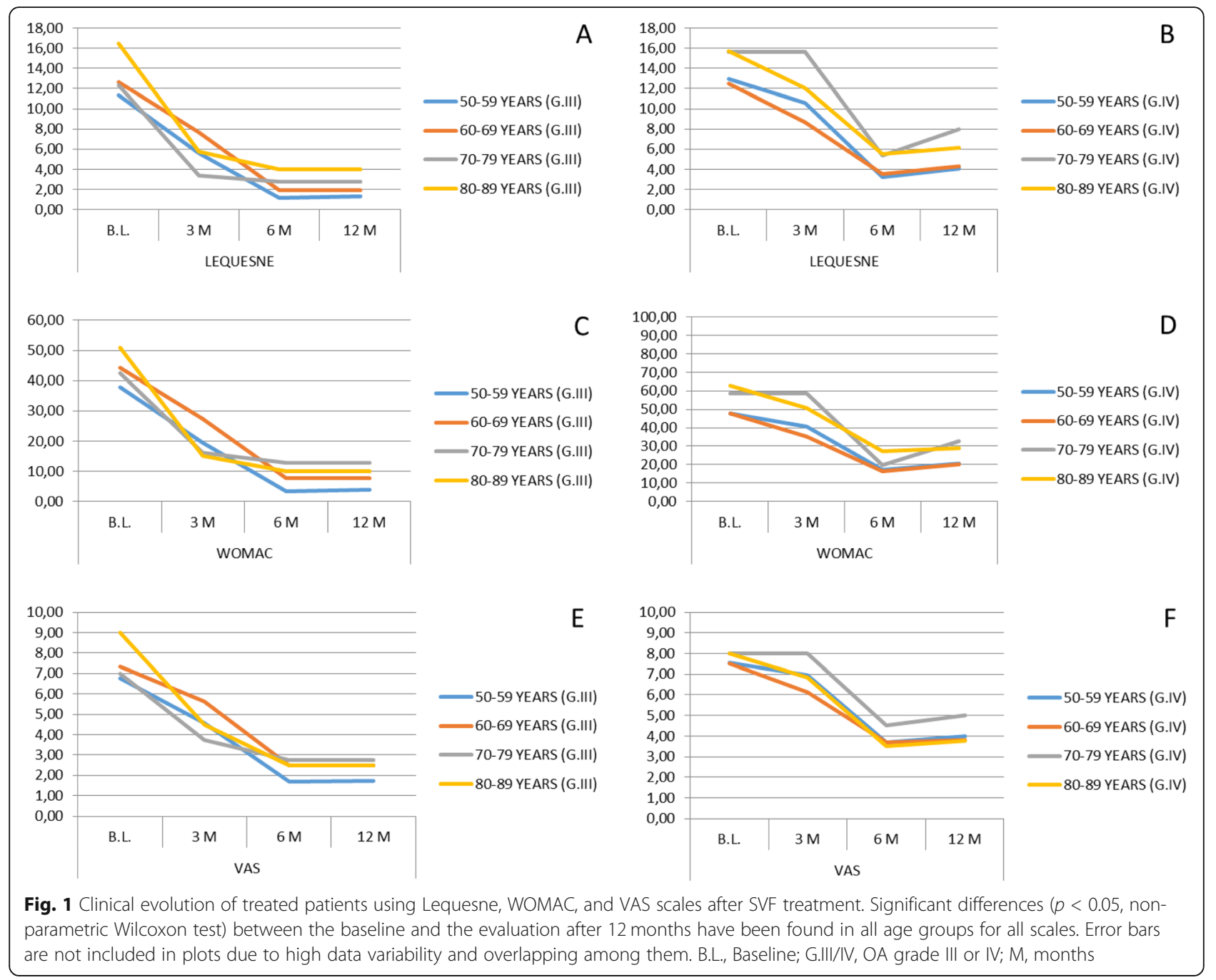

index. The average patient satisfaction rate regardless of their age (expressed as a percentage) was $85.8 \%$ in the grade III gonarthrosis group and $76.2 \%$ in the grade IV gonarthrosis group.

Regarding the ultrasound control, the study of the clarity and integrity of the soft tissue-cartilage interface showed a slight improvement in the grade IV group and a clear improvement in the grade III group. No significant changes were observed in any group with respect to thickness measurement. With respect to the ultrasound assessment of synovial effusion, an evident improvement was observed in the grade III group, being this improvement smaller in the grade IV group (Fig. 2a, b).

\section{Molecular profile of synovial fluid}

The catabolic and anabolic profiles observed in synovial fluid by measuring the levels of metalloproteinase 2 (MMP2) and insulin-like growth factor type 1 (IGF1) decreased $80.24 \%$ and increased $330.64 \%$, respectively. Likewise, analyzing the pro-inflammatory and antiinflammatory profiles observed in synovial fluid by evaluation of pro-inflammatory cytokines (IL1 $\beta$, IL6, and IL8) and anti-inflammatory cytokines (IL10), decreased by $32.26 \%$ in the case of IL1 $\beta, 58.25 \%$ in the case of IL6, and $36.77 \%$ in the case of IL8 and increased $70.80 \%$ in the case of IL10 (Fig. 2c, d). All results in the figures are expressed as picograms per milliliter of synovial fluid.

\section{SVF characterization}

After doing a previous dilution, the number of nucleated cells present in the original samples was $3.21 \times 10^{6} \pm$ $0.44 \times 10^{6}$ per milliliter, with an average vitality (viability) of $82 \pm 9 \%$.

The results of the phenotypic characterization of three representative SVF samples are reflected in Fig. 2e. The expression of different markers is showed in percent with respect to total nucleated cells. 

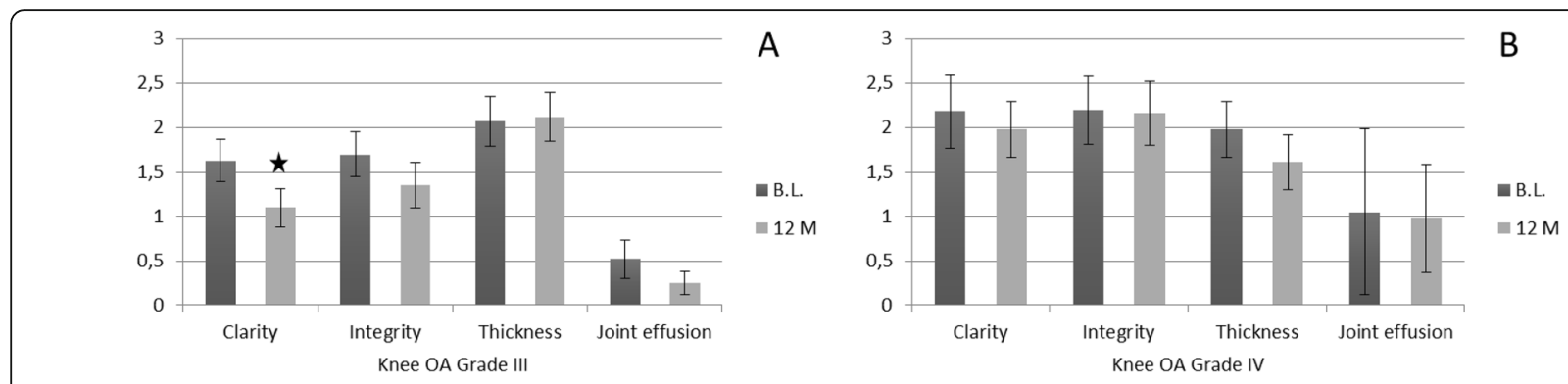

B
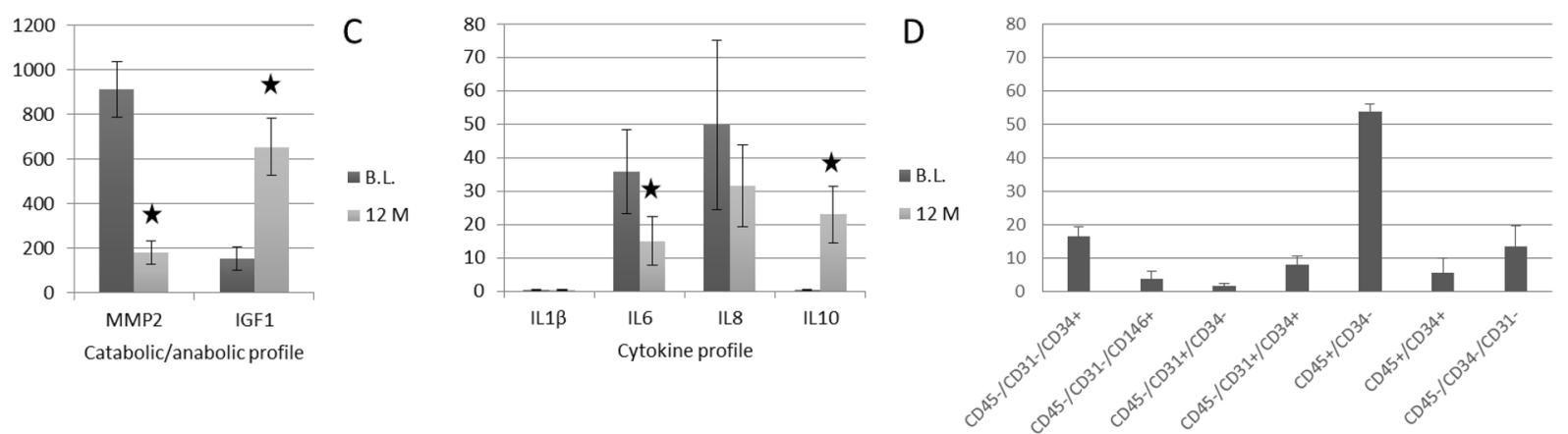

E

Fig. 2 Evolution of diferent markers in knee OA treatment and SVF cell characterization. B.L., Baseline; M, months; black stars indicate significant differences $(p<0.05$, non-parametric Wilcoxon test)

\section{Discussion}

\section{SVF clinical effect in knee OA}

The use of SVF has great potential as a therapeutic agent in regenerative medicine, especially in human orthopedic applications. Preliminary clinical studies suggest that its use is safe and effective in the treatment of osteoarthritis $[25,26]$, which is reproduced in our study in which safety and efficacy have been evaluated by monitoring patients for 1 year. Adverse reactions observed were mild and transient, mostly abdominal discomfort related with liposuction procedure. As in other studies, we have not found severe complications in elderly patients [27]. Regarding the infiltration of SVF, the most frequent adverse effect was a mild and transient synovitis, probably caused by the volume injected, as described by other authors [28]. Some disadvantages of this technique are the processing time from tissue harvest to SVF isolation (60-90 min), and in some cases difficulties to obtain enough lipoaspirate volume from very lean patients (low body mass index).

Based on the type of clinical study carried, the inclusion of appropriate control group was not possible, and we understand that the data collected and possible conclusions drawn could be biased. Nevertheless, from a functional and pain point of view, the satisfaction rate of patients with grade III osteoarthritis was higher than that of patients with grade IV in all age groups, except in the older age group, which suggests that the more advanced degrees of the pathology entail a minor clinical improvement, or perhaps the expectations of the patients most affected by the pathology were higher. A more advanced disease stage would be also much more difficult to treat or respond to the treatment applied. In any case, in all age groups, all the indexes studied improved and remained so for a year, which demonstrates a clear reduction of pain and improved functionality in the knees treated with SVF. The results suggest that the most pronounced improvement occurs between the third and sixth months, but the assessments used are subjective, and we believe that drawing conclusions on this aspect could be premature. Other studies have reported an extended follow-up period of 2 years [29], finding similar positive results, although they suggest that efficacy may decrease after this initial period of treatment. There are still many questions to answer, such as the possibility of optimizing the therapeutic effect with repeated doses, the influence of cell dose used, or the possibility of testing different routes of administration, among others. Additional studies should also be carried out with or without platelet rich plasma [30], with or without hyaluronic acid [28], and even comparing SVF versus microfracture treatment [31].

\section{Synovial fluid evaluation and $\mathrm{OA}$ etiology}

From a biochemical point of view, our results from synovial fluid analysis show a change in the molecular profile towards an anti-inflammatory phenotype and therefore are consistent with the observed clinical and 
ultrasound improvements observed. We were unable to find an equivalent study carried out under the same conditions to compare results, but other authors have also studied biochemical profiles in similar situations obtaining comparable results [32-37]. Moreover, even with a different treatment, for example, with hyaluronic acid, a change in the cytokine profile towards that typically anti-inflammatory phenotype is also observed [38]. All these results seem to indicate that the clinical improvement observed in OA, regardless of treatment, could be related with modified molecular profiles in the synovial fluid overtime.

\section{Infrapatellar fat pad as main driver of knee $O A$ pathophysiology}

Speaker and Fleshner suggested in 2012 that there could be a connection between the production of IL1 $\beta$ and the development of visceral fat [39]. It does not seem unreasonable to think that there could also be an answer to this mediator by the fatty tissue that constitutes the infrapatellar fat pad. On the other hand, Fain et al. in 2006 demonstrated that macrophages are primarily responsible for the secretion of pro-inflammatory mediators by adipose tissue [40]. In addition, other studies describe macrophages also as directly responsible for the inflammatory and destructive action in OA [41]. These macrophages can be found in synovial tissue, but also in the IFP, which makes them candidates for effectors of joint inflammation. In fact, the different concentration of adipokines in synovial tissue and blood plasma in OA [42] suggests that their production is local, that is, produced by intra-articular fatty tissue. Moreover, in 2011, Klein-Wieringa et al. demonstrated, by analyzing the Hoffa's fat discarded when performing the prosthetic replacement, that it presented a pro-inflammatory phenotype and behaved like an authentic paracrine organ, generator of pro-inflammatory cytokines (IL6, IL8, and $\mathrm{TNF} \alpha$ ) that end up being related to the genesis and progression of knee OA [34]. In fact, IFP could have a leading role in the development of the disease, a hypothesis initially suggested by Ushiyama et al. in 2003 [43] and reconsidered years later by Distel et al. [44] and Clockaerts et al. [45]. Moreover, in the same study [34], they found differences in cell composition, such as in the macrophage immunophenotype and in the secretome, between the SVF of IFP and the SVF of adipose tissue subcutaneously, opening the door to relate the therapeutic effect in OA of SVF injection obtained subcutaneously with rebalancing the cellular and molecular composition of local adipose tissue. For all this, we deduce that the mechanism of therapeutic action of the intra-articular SVF implant could be mainly due to the immunomodulatory effect of the MSCs (an other immunocompetent cells present) of this cellular solution on IFP, which with improved homeostatic capacity, would regulate the progression of the disease and thus the clinical effect observed.

\section{SVF crosstalk}

Native MSCs (in vivo) reside in the perivascular space in a quiescent state until chemical signals released from damaged tissues activate them, migrating to the site of injury and producing bioactive molecules that restore tissue homeostasis [46] by regulating the inflammatory response, reducing apoptosis, and recruiting progenitors of host tissue, in addition to direct differentiation into specific cells of the injured tissue. Therefore, theoretically, the infiltration of SVF into a pro-inflammatory environment would activate the MSCs (adaptive response) present in the SVF, which by producing mainly IL- 1 Ra (IL-1 $\beta$ antagonist), prostaglandin 2, IDO, IL-4, IL-10, and TGF $\beta$, would modulate the immune cells present (local and grafted). This would produce a cascade of additive molecular interactions favoring immunotolerant and anti-inflammatory mechanisms. Polarization of macrophages to type M2, which in turn would express more IL-4, IL-10, and IGF-1, and would inhibit their production of IL-12 and TNF $\alpha$. Inhibition of proliferation and activation of cytotoxic and effector $\mathrm{T}$ lymphocytes (inhibition of the production of TNFa and IFN $\gamma$ ) in favor of regulatory lymphocytes (Treg) related to immunosuppressive processes. Inhibition also of proliferation, differentiation, and migration (and therefore of the production of immunoglobulins) of $\mathrm{B}$ lymphocytes. Inhibition of the proliferation of NK cells (and therefore of IFNy production) and reduction of apoptosis and ROS, by inhibition of neutrophils and preventing mast cell degranulation. Finally, they also seem to have an effect on dendritic cells as they increase their expression of IL-10 and reduce that of TNF $\alpha$ (reviewed by Brennen et al.) [47]. This entire chain of events has a direct effect on the reduction of metalloproteinase levels and results in the reduction of pro-inflammatory molecules and increase of anti-inflammatory ones in the joint environment (according to our analysis of the inflammatory profile of synovial fluid before and after treatment). This stops the vicious pro-degenerative circle, slowing the progression of the disease and restoring tissue homeostasis.

Although the MSCs seem to carry, in principle, the greatest biological potency, the therapeutic effect of SVF cells on the progression of OA with all cells present, and the synergies between them and the treated tissue can be also involved.

\section{Conclusions}

We conclude that intra-articular SVF infiltration for knee OA treatment is safe and effective. We propose that applied SVF cells cause a cascade of molecular and structural events that, through complex interactions 
between IFP and SVF, re-educates the intra-articular fatty tissue towards a homeostatic, protective, and antiinflammatory function. This mechanism would ultimately promote the restructuring and regeneration of damaged tissues.

It would be desirable to study and evaluate, in an animal model of knee OA and with labelled SVF cells, the progression at different times of histopathological changes in IFP, articular cartilage, and synovial membrane and fluid, to be able to understand in depth the observed therapeutic effect. This would allow to refute or confirm the proposed hypothesis.

\section{Abbreviations}

SVF: Stromal vascular fraction; IFP: Infrapatellar fat pad; MSCs: Mesenchymal stem cells; OA: Osteoarthritis; EPCs: Endothelial progenitor cells; PDGF: Platelet-derived growth factor; ATMP: Advanced Therapy Medicinal Product; VEGF: Vascular endothelial growth factor; ECs: Endothelial cells; IL: Interleukin; VAS: Visual Analogue Scale; WOMAC: Western Ontario and Mc Master Universities Osteoarthritis Index; MMP: Metalloproteinases; IGF: Insulin growth factor; TNFa: Tumor necrosis factor alpha; LIF: Leukemia inhibitory factor; DAMPS: Damage-associated molecular patterns; TLR: Toll-like receptors; IDO: Indoleamine dioxygenase; IFNy: Interferon gamma; Treg: Regulatory T cells; NK: Natural killer cells; PTOA: Post-traumatic osteoarthritis; B.L.: Baseline

\section{Acknowledgments}

We want to thank the medical and scientific team of the Phisiup clinic for their valuable support and willingness to carry out this study. We would like to especially thank Mrs. Carmen Iglesias Moreno for her initial documentation work.

\section{Authors' contributions}

Juan Pedro Lapuente: conception and design, collection and assembly of data, data analysis and interpretation, manuscript writing, and final approval of manuscript. Severiano Dos-Anjos: manuscript writing and final approval of manuscript. Alejandro Blázquez-Martínez: data interpretation, manuscript writing, and final approval of manuscript.

\section{Funding}

This work was carried out thanks to the personal financial contribution of the first author and the collaboration of Lyposmol Biotech kindly providing the devices to obtain the SVF.

\section{Availability of data and materials}

The data and materials are conveniently explained in the main text. If any reader needs any additional data, they can write freely to the corresponding author.

\section{Ethics approval and consent to participate}

The use of the ADSC system device does not need approval by any ethical committee as it is a homologous transplant. In addition, the treatment was carried out before the publication of RD 1090/2015 of December 4, by which the Ethics Committees of Drug Research are regulated in Spain. Of course, patients were informed both verbally and in writing by informed consent.

\section{Consent for publication}

Not applicable

\section{Competing interests}

All authors work directly or indirectly for Lyposmol Biotech, a biotechnology company whose objectives include research, development, and commercialization of Regenerative Medicine and Cell Therapy products.

\section{Author details}

${ }^{1}$ Health Sciences PhD program, Universidad Católica de Murcia UCAM, 9 Campus de los Jerónimos n¹35, 30107 Guadalupe, Murcia, Spain. ${ }^{2}$ Lyposmol Biotech, Isabel Colbrand, 6, 28050 Madrid, Spain.
Received: 25 September 2019 Accepted: 2 April 2020

Published online: 09 April 2020

\section{References}

1. Seoane-Mato D, Sánchez-Piedra C, Silva-Fernández L, Sivera F, Blanco FJ, Pérez Ruiz F, et al. Prevalence of rheumatic diseases in adult population in Spain (EPISER 2016 study): aims and methodology. Reumatol Clin. 2019; 15(2):90-6.

2. Zhang W, Moskowitz RW, Nuki G, et al. OARSI recommendations for the management of hip and knee osteoarthritis, Part II: Oarsi evidence-based, Expert Consensus Guidelines. Osteoarthritis Cartilage. 2008;16:137-62.

3. Lohmander LS, Roos EM. Clinical update: treating osteoarthritis. Lancet. 2007;370:2082-4.

4. Vanlauwe J, Saris DB, Victor J, et al. Five year outcome of characterized chondrocyte implantation versus microfracture for symptomatic cartilage defects of the knee: early treatment matters. Am J Sports Med. 2011;39: 2566-74.

5. von der Mark K, Gauss V, von der Mark H, et al. Relationship between cell shape and type of collagen synthesised as chondrocytes lose their cartilage phenotype in culture. Nature. 1977;267:531-2

6. Jo CH, Lee YG, Shin WH, Kim H, Chai JW, Jeong EC, Kim JE, Shim H, Shin JS, Shin IS, Ra JC, Oh S, Yoon KS. Intra-articular injection of mesenchymal stem cells for the treatment of osteoarthritis of the knee: a proof-of-concept clinical trial. Stem Cells. 2014;32(5):1254-66.

7. Michalek J, Moster R, Lukac L, Proefrock K, Petrasovic M, Rybar J, Capkova M, Chaloupka A, Darinskas A, Michalek J Sr, Kristek J, Travnik J, Jabandziev P, Cibulka M, Holek M, Jurik M, Skopalik J, Kristkova Z, Dudasova Z. Stromal vascular fraction cells of adipose and connective tissue in people with osteoarthritis: a case control prospective multi-centric non-randomized study. Global Surg. 2017;3(3):5-9.

8. Yokota N, Yamakawa M, Shirata T, Kimura T, Kaneshima $H$. Clinical results following intra-articular injection of adipose-derived stromal vascular fraction cells in patients with osteoarthritis of the knee. Regen Ther. 2017;6: 108-12.

9. De Miguel MP, Fuentes-Julián S, Blázquez-Martínez A, Pascual CY, Aller MA, Arias J, Arnalich-Montiel F. Immunosuppressive properties of mesenchymal stem cells: advances and applications. Curr Mol Med. 2012;12(5):574-91.

10. Bourin P, Bunnell BA, Casteilla L, Dominici M, Katz AJ, March KL, Redl H, Rubin JP, Yoshimura K, Gimble JM. Stromal cells from the adipose tissuederived stromal vascular fraction and culture expanded adipose tissuederived stromal/stem cells: a joint statement of the International Federation for Adipose Therapeutics and Science (IFATS) and the International Society for Cellular Therapy (ISCT). Cytotherapy. 2013;15(6):641-8.

11. Vangsness CT Jr, Farr J 2nd, Boyd J, Dellaero DT, Mills CR, LeRoux-Williams M. Adult human mesenchymal stem cells delivered via intra-articular injection to the knee following partial medial meniscectomy: a randomized, double-blind, controlled study. J Bone Joint Surg Am. 2014;96:90-8.

12. Traktuev DO, Merfeld-Clauss S, Li J, Kolonin M, Arap W, Pasqualini R, Johnstone $\mathrm{BH}$, March $\mathrm{KL}$. A population of multipotent CD34-positive adipose stromal cells share pericyte and mesenchymal surface markers, reside in a periendothelial location, and stabilize endothelial networks. Circ Res. 2008;102:77-85.

13. Traktuev DO, Prater DN, Merfeld-Clauss S, Sanjeevaiah AR, Saadatzadeh MR, Murphy $\mathrm{M}$, Johnstone $\mathrm{BH}$, Ingram DA, March KL. Robust functional vascular network formation in vivo by cooperation of adipose progenitor and endothelial cells. Circ Res. 2009;104:1410-20.

14. Koh YJ, Koh BI, Kim H, Joo HJ, Jin HK, Jeon J, Choi C, Lee DH, Chung JH, Cho CH, Park WS, Ryu JK, Suh JK, Koh GY. Stromal vascular fraction from adipose tissue forms profound vascular network through the dynamic reassembly of blood endothelial cells. Arterioscler Thromb Vasc Biol. 2011; 31:1141-50

15. Morris DL, Oatmen KE, Wang T, DelProposto JL, Lumeng CN. CX3CR1 deficiency does not influence trafficking of adipose tissue macrophages in mice with diet-induced obesity. Obesity (Silver Spring). 2012;20:1189-99.

16. Potente M, Gerhardt H, Carmeliet P. Basic and therapeutic aspects of angiogenesis. Cell. 2011;146:873.

17. Dong Z, Peng Z, Chang Q, Lu F. The survival condition and immunoregulatory function of adipose stromal vascular fraction (SVF) in the early stage of nonvascularized adipose transplantation. PLoS One. 2013;8: e80364. 
18. van Buul GM, Villafuertes E, Bos PK, Waarsing JH, Kops N, Narcisi R, Weinans $H$, Verhaar JA, Bernsen MR, van Osch GJ. Mesenchymal stem cells secrete factors that inhibit inflammatory processes in short-term osteoarthritic synovium and cartilage explant culture. Osteoarthritis Cartilage. 2012;20(10): 1186-96.

19. Leijs MJ, van Buul GM, Lubberts E, Bos PK, Verhaar JA, Hoogduijn MJ, van Osch GJ. Effect of arthritic synovial fluids on the expression of immunomodulatory factors by mesenchymal stem cells: an explorative in vitro study. Front Immunol. 2012;3:231.

20. Manferdini C, Maumus M, Gabusi E, Piacentini A, Filardo G, Peyrafitte JA, Jorgensen C, Bourin P, Fleury-Cappellesso S, Facchini A, Noël D, Lisignoli G. Adipose-derived mesenchymal stem cells exert antiinflammatory effects on chondrocytes and synoviocytes from osteoarthritis patients through prostaglandin E2. Arthritis Rheum. 2013; 65(5):1271-81.

21. Topoluk N, Steckbeck K, Siatkowski S, Burnikel B, Tokish J, Mercuri J. Amniotic mesenchymal stem cells mitigate osteoarthritis progression in a synovial macrophage-mediated in vitro explant coculture model. J Tissue Eng Regen Med. 2018;12(4):1097-110.

22. Lequesne MG, Mery C, Samson M, Gerard P. Indexes of severity for osteoarthritis of the hip and knee validation - value in comparison with other assessment tests. Scand J Rheumatology. 1987;Supp1.65:85439.

23. Feixas G, Pucurull O, Roca C, Paz C, García-Grau E, Bados A. Escala de Satisfacción con el tratamiento recibido (CRES-4): La versión en español. Revista de Psicoterapia. 2012;89:51-8.

24. Grassi W, Lamanna G, Farina A, Cervini C. Sonographic imaging of normal and osteoarthritic cartilage. Semin Arthritis Rheum. 1999;28(6):398-403.

25. Strioga M, Viswanathan S, Darinskas A, Slaby O, Michalek J. Same or not the same? Comparison of adipose tissue-derived versus bone marrow-derived mesenchymal stem and stromal cells. Stem cells and development. 2012; 21(14):2724-52.

26. Fodor PB, Paulseth SG. Adipose derived stromal cell (ADSC) injections for pain management of osteoarthritis in the human knee joint. Aesthetic Surg J. 2015;36(2):229-36

27. Michalek J, Vrablikova A, Darinskas A, Lukac L, Prucha J, Skopalik J, et al. Stromal vascular fraction cell therapy for osteoarthritis in elderly: multicenter case-control study. J Clin Orthopaedics Trauma. 2019;10(1):76-80.

28. Hong Z, Chen J, Zhang S, Zhao C, Bi M, Chen X, et al. Intra-articular injection of autologous adipose-derived stromal vascular fractions for knee osteoarthritis: a double-blind randomized self-controlled trial. Int Orthopaed. 2018;43(5):1123-34.

29. Tran TDX, Wu CM, Dubey NK, Deng YH, Su CW, Pham TT, Thi Le PB, Sestili P, Deng WP. Time- and Kellgren'Lawrence grade-dependent changes in intraarticularly transplanted stromal vascular fraction in osteoarthritic patients. Cells. 2019;8:4.

30. Gibbs N, Diamond R, Sekyere EO, Thomas WD. Management of knee osteoarthritis by combined stromal vascular fraction cell therapy, plateletrich plasma, and musculoskeletal exercises: a case series. J Pain Res. 2015;8: 799-806.

31. Bisicchia S, Bernardi G, Pagnotta SM, Tudisco C. Micro-fragmented stromalvascular fraction plus microfractures provides better clinical results than microfractures alone in symptomatic focal chondral lesions of the knee. Knee Surg Sports Traumatol Arthrosc. 2019. https://doi.org/10.1007/s00167019-05621-0.

32. Neidel J, Blum WF, Schaeffer HJ, Schulze M, Schönau E, Lindschau J, et al. Elevated levels of insulin-like growth factor (IGF) binding protein-3 in rheumatoid arthritis synovial fluid inhibit stimulation by IGF-I of articular chondrocyte proteoglycan synthesis. Rheumatol Int. 1997;17(1):29-37.

33. Schneiderman R, Rosenberg N, Hiss J, Lee P, Liu F, Hintz RL, et al. Concentration and size distribution of insulin-like growth factor-1 in human normal and osteoarthritic synovial fluid and cartilage. Archiv Biochem Biophys. 1995;324(1):173-88.

34. Klein-Wieringa IR, Kloppenburg M, Bastiaansen-Jenniskens YM, et al. Extended report: the infrapatellar fat pad of patients with osteoarthritis has an inflammatory phenotype. Ann Rheum Dis. 2011;70(5):851-7.

35. Heard BJ, Martin L, Rattner JB, Frank CB, Hart DA, Krawetz R. Matrix metalloproteinase protein expression profiles cannot distinguish between normal and early osteoarthritic synovial fluid. BMC Musculoskelet Disord. 2012;13:126.

36. Mabey T, Honsawek S, Tanavalee A, Yuktanandana P, Wilairatana V, Poovorawan Y. Comparison of synovial fluid cytokine levels between traumatic knee injury and end-stage osteoarthritis. Biomarkers. 2016;21(7): 639-44.

37. Siqueira MB, Frangiamore S, Klika AK, Gajewski N, Barsoum WK, Higuera CA. Plasma and synovial fluid inflammatory cytokine profiles in primary knee osteoarthritis. J Knee Surg. 2017;30(2):128-33.

38. Kusayama Y, Akamatsu Y, Kumagai K, Kobayashi H, Aratake M, Saito T. Changes in synovial fluid biomarkers and clinical efficacy of intra-articular injections of hyaluronic acid for patients with knee osteoarthritis. J Exp Orthop. 2014;1(1):16.

39. Speaker KJ, Fleshner M. Interleukin-1 beta: a potential link between stress and the development of visceral obesity. BMC Physiol. 2012;12:8.

40. Fain JN, Madan AK, Hiler ML, et al. Comparison of the release of adipokines by adipose tissue, adipose tissue matrix, and adipocytes from visceral and subcutaneous abdominal adipose tissues of obese humans. Endocrinology. 2004;145(5):2273-82

41. Bondeson J, Blom AB, Wainwright $S$, et al. The role of synovial macrophages and macrophage-produced mediators in driving inflammatory and destructive responses in osteoarthritis. Arthritis Rheum. 2010;62(3):647-57.

42. Presle $N$, Pottie $P$, Dumond $H$, et al. Differential distribution of adipokines between serum and synovial fluid in patients with osteoarthritis. Contribution of joint tissues to their articular production. Osteoarthritis Cartilage. 2006;14(7):690-5.

43. Ushiyama T, Chano T, Inoue K, Matsusue Y. Cytokine production in the infrapatellar fat pad: another source of cytokines in knee synovial fluids. Ann Rheum Dis. 2003;62(2):108-12.

44. Distel E, Cadoudal T, Durant S, Poignard A, Chevalier X, Benelli C. The infrapatellar fat pad in knee osteoarthritis: an important source of interleukin-6 and its soluble receptor. Arthritis Rheum. 2009;60(11):3374-7.

45. Clockaerts S, Bastiaansen-Jenniskens YM, Runhaar J, et al. The infrapatellar fat pad should be considered as an active osteoarthritic joint tissue: a narrative review. Osteoarthritis Cartilage. 2010;18(7):876-82.

46. Caplan Al. MSCs: the sentinel and safe-guards of injury. J Cell Physiol. 2016; 231:1413-6.

47. Brennen WN, Denmeade SR, Isaacs JT. Mesenchymal stem cells as a vector for the inflammatory prostate microenvironment. Endocr Relat Cancer. 2013; 20(5):R269-90.

\section{Publisher's Note}

Springer Nature remains neutral with regard to jurisdictional claims in published maps and institutional affiliations.
Ready to submit your research? Choose BMC and benefit from:

- fast, convenient online submission

- thorough peer review by experienced researchers in your field

- rapid publication on acceptance

- support for research data, including large and complex data types

- gold Open Access which fosters wider collaboration and increased citations

- maximum visibility for your research: over $100 \mathrm{M}$ website views per year

At BMC, research is always in progress.

Learn more biomedcentral.com/submissions 